\title{
Reference Stress Approach for Fracture Assessment of Extrados Circumferential Through-Wall Crack between Elbow and Pipe under Internal Pressure
}

\author{
Jirapong Kasivitamnuay* and Pairod Singhatanadgid \\ Department of Mechanical Engineering, Faculty of Engineering, Chulalongkorn University, Phayathai Rd., \\ Wangmai, Patumwan, Bangkok 10330, Thailand \\ *E-mail: jirapong.K@chula.ac.th (Corresponding author)
}

\begin{abstract}
The fracture assessment of a cracked component can provide technical support for an effective maintenance and a prevention of catastrophic accident. The present study applies the reference stress method to extend the $J$-integral solution from the finite element analysis for the Ramberg-Osgood stress-strain relationship to other types of stress-strain relationship. The problem in this study is an extrados circumferential through-wall crack at the interface between elbow and pipe subjected to internal pressure. The finite element results from the literature were analyzed to determine the optimized reference pressure. The fracture loads predicted by the reference-stress-based failure assessment curve which incorporated with the optimized reference pressure were compared with those predicted by the finite-element-based failure assessment curve. The failure load predicted from the reference-stress-based failure assessment curve deviated from that predicted from the finiteelement-based failure assessment curve within the range of $-7 \%$ to $11 \%$.
\end{abstract}

Keywords: J-integral, circumferential through-wall crack, pipe, elbow, reference stress method, failure assessment diagram.

ENGINEERING JOURNAL Volume 22 Issue 6

Received 4 June 2018

Accepted 30 August 2018

Published 4 December 2018

Online at http://www.engj.org/

DOI:10.4186/ej.2018.22.6.151 


\section{Introduction}

Piping system is an important structural component in industrial plants. When a crack-like flaw is detected in the component due to in-service loading or environmental effects, engineers have to take an appropriate action, e.g. continue operation, rerate an operating condition, or repair the component etc. A reasonable decision is important to avoid unnecessary maintenance cost and also to prevent a catastrophic accident. Integrity assessment can provide a technical support for this decision-making process.

Standard practice for integrity assessment of a cracked component, e.g. API 579 [1], adopts the failure assessment diagram (FAD) approach. The information about a component at the present time, such as dimensions, material, crack, service load etc., is analyzed to determine the tendency of the component to fail by unstable fracture and plastic collapse in terms of specific parameters namely a toughness ratio (also called a stress intensity factor ratio) and a load ratio, respectively. By plotting these parameters on the FAD, the assessment point which represents the current status of the component is obtained. The assessment point is then compared with the failure assessment curve (FAC). If the assessment point lies below or on the FAC, the component is predicted to be safe and it is allowed to continue an operation for a certain period of time. However, if this is not the case, another action (e.g. repair, replace etc.) has to be carried out.

Several options of the FAC are available for fracture assessment. The most accurate FAC is derived from $J$-integral solution. However, $J$ solution depends not only on a particular cracked component and applied load but also on material deformation behavior, i.e. a true tensile stress-strain curve. The available solutions which are determined by finite element (FE) method were typically adopted the Ramberg-Osgood (RO) type stressstrain relation [2]. If a material exhibits a deformation behavior which does not fit the RO equation, e.g. carbon steel [3], cold-worked stainless steel [4] etc., the application of RO-based $J$ solutions without modifications may result in an inaccurate value of $J$ and FAC. Recently, Kamaya [5] proposed a new $J$ estimation scheme. But his approach utilized the $J$ solution for a bi-linear stress-strain relation to estimate $J$ for a specific type of stress-strain relation that is not fit RO equation. However, an application of this approach was limited by the availability of the $J$ solution for a bi-linear stress-strain relation which was very limited. Ainsworth [6] observed that the dependence of a fully-plastic $J$ solution on the strain hardening behavior can be minimized if the applied load is normalized by a reference load instead of a limit load. As a result, he obtained a $J$ estimation equation and a reference stress (RS) based FAC, which are applicable to any types of stress-strain relation. The reference stress method has been further refined and successfully applied to various components in the piping system [7-18]. Furthermore, it has been incorporated into many standard procedures for structural integrity assessment. Therefore, it might be the most practical approach for an estimation of $J$ and FAC.

In a piping system, crack can initiate at any locations, e.g. straight pipe, elbow, interface between elbow and pipe etc. For a straight pipe, applications of the reference stress have been extensively done, e.g. axial through-wall crack under pressure [7, 13]; circumferential through-wall crack under combined tension and in-plane bending [8, 9, 13]; axial constant-depth surface crack under internal pressure [11, 13]; circumferential semielliptical surface crack under tension, in-plane bending and internal pressure $[10,12,18]$; circumferential constant-depth surface crack under tension, in-plane bending and internal pressure [13]. For an elbow, much less applications of the reference stress method have been reported, e.g. axial through-wall crack at crown under pressure and in-plane bending [14]; circumferential through-wall crack located in the center of the elbow at the intrados or at the extrados and subjected to in-plane bending [15]. Similarly, applications of the reference stress method to the crack problem at the interface between straight pipe and elbow were limited to the case of circumferential through-wall crack [16] and circumferential constant-depth surface crack under in-plane bending [17]. Recently, Jang et al. [19, 20] reported a completed set of the fracture mechanics parameters of circumferential through-wall crack at the interface between elbow and straight pipe under internal pressure. However, application of the reference stress method to this problem has not been reported.

This study analyses the fully-plastic $J$ solution published by Jang et al. [20] to determine the reference pressure for incorporating with the reference stress based FAC of an extrados circumferential through-wall cracked at the interface between straight pipe and elbow subjected to internal pressure. Section 2 derives the estimation equations of $J$ and FAC by the reference stress method. Section 3 describes how to determine the reference pressure and reports the result. Section 4 evaluates the accuracy of RS-based FAC by comparing with FE-based FAC. 


\section{The Reference Stress Method}

This section presents a derivation of the estimation equations of $J$ and FAC for the cracked component shown in Fig. 1 by the reference stress method. An elbow with a bend radius of $R$ is joined to a straight pipe having the same cross-sectional dimension: a mean radius of $r_{m}$ and a wall thickness of $t$. At the interface, the extrados through-wall crack with a surface length of $2 a$ (or crack angle $2 \theta$ ) exists. The component is subjected to an internal pressure, $p$.

Consider the following uniaxial stress-strain relation, i.e. the Ramberg-Osgood (RO) equation,

$$
\frac{\varepsilon}{\varepsilon_{Y}}=\frac{\sigma}{\sigma_{Y}}+\alpha\left(\frac{\sigma}{\sigma_{Y}}\right)^{n}
$$

where $\varepsilon_{Y}$ is yield strain, $\sigma_{Y}$ is yield stress, $\alpha$ and $n$ are strain hardening coefficient and exponent, respectively.

The $J$ solution can be estimated from the elastic component $J_{e}$ and the fully-plastic component $J_{p}$ by the following equation,

$$
J=J_{e}+J_{p} .
$$

The elastic component of $J$ (i.e. $J_{e}$ ) can be expressed in terms of the stress intensity factor $K$ by

$$
J_{e}=\frac{\left[K\left(a_{e f f}\right)\right]^{2}}{E^{\prime}}
$$

where $E^{\prime}=E$ for the plane stress problem and $E^{\prime}=E /\left(1-v^{2}\right)$ for the plane strain problem; $a_{\text {eff }}$ is an effective half-crack length, which is defined in Ref. [2] as

$$
a_{e f f}=a+\frac{1}{\beta \pi\left[1+\left(p / p_{L}\right)^{2}\right]}\left(\frac{n-1}{n+1}\right)\left(\frac{K}{\sigma_{Y}}\right)^{2},
$$

where $\beta=2$ for the plane stress problem and $\beta=6$ for the plane strain problem. The $K$ solution for the present problem is taken from Ref. [19] and is summarized for completeness in appendix A.

For the present problem, the fully-plastic component of $J$ (i.e. $J_{p}$ ) for material obeying the RO equation can be written as [20]

$$
J_{p}=\alpha \sigma_{Y} \varepsilon_{Y} \theta r_{m} \cdot\left(1-\frac{\theta}{\pi}\right) \cdot h_{1}\left(\frac{r_{m}}{t}, \frac{R}{r_{m}}, \frac{\theta}{\pi}, n\right) \cdot\left(\frac{p}{p_{L}}\right)^{n+1},
$$

where $h_{1}$ is a plastic influence function which is tabulated in Table 2 of Ref. [20], and $p_{L}$ is a limit pressure. The limit pressure adopted in Eq. (5) is that used in case of a straight pipe with a circumferential throughwall crack, which is expressed by

$$
p_{L}=\frac{2 \sigma_{Y} t}{\pi r_{m}}\left[\pi-\theta-2 \sin ^{-1}\left(\frac{\sin \theta}{2}\right)\right]
$$

By changing the normalizing pressure from the limit pressure $p_{L}$ to the reference pressure $p_{r e f}$, Eq. (5) can be rewritten as

where

$$
\begin{gathered}
J_{p}=\alpha \sigma_{Y} \varepsilon_{Y} \theta r_{m} \cdot\left(1-\frac{\theta}{\pi}\right) \cdot h_{1}^{*} \cdot\left(\frac{p}{p_{r e f}}\right)^{n+1}, \\
h_{1}^{*}=h_{1}\left(\frac{r_{m}}{t}, \frac{R}{r_{m}}, \frac{\theta}{\pi}, n\right) \cdot\left(\frac{p_{r e f}}{p_{L}}\right)^{n+1} .
\end{gathered}
$$

If $p_{r e f}$ is chosen such that the dependence of $h_{1}^{*}$ on $n$ is minimized, then the elastic component of $J$ can be estimated from Eq. (7) by substituting $\alpha=1$ and $n=1$ into the equation, which yields 


$$
J_{e}=\sigma_{Y} \varepsilon_{Y} \theta r_{m} \cdot\left(1-\frac{\theta}{\pi}\right) \cdot h_{1}^{*} \cdot\left(\frac{p}{p_{\text {ref }}}\right)^{2} .
$$

Dividing Eq. (5) by Eq. (9) yields the ratio of fully-plastic and elastic components of $J$ as

$$
\frac{J_{p}}{J_{e}} \approx \alpha \cdot\left(\frac{p}{p_{r e f}}\right)^{n-1} .
$$

Define the reference stress $\sigma_{r e f}$ as

where $L_{r}$ is a load ratio and is defined as

$$
\sigma_{\text {ref }}=L_{r} \sigma_{Y}
$$

$$
L_{r}=\frac{p}{p_{r e f}}
$$

Rewriting Eq. (10) by using Eqs. (11) and (12) yields

$$
\frac{J_{p}}{J_{e}} \approx \alpha\left(\frac{\sigma_{r e f}}{\sigma_{Y}}\right)^{n-1} .
$$

From Eq. (1), the plastic component of the reference strain $\varepsilon_{r e f}^{p}$ at $\sigma=\sigma_{r e f}$ is

$$
\varepsilon_{r e f}^{p}=\alpha \varepsilon_{Y}\left(\frac{\sigma_{r e f}}{\sigma_{Y}}\right)^{n} .
$$

Substituting Eq. (14) into Eq. (13) and applying the relationship $E=\sigma_{Y} / \varepsilon_{Y}$, where $E$ is the elastic modulus, yields

$$
\frac{J_{p}}{J_{e}} \approx \frac{E \varepsilon_{r e f}^{p}}{\sigma_{r e f}} .
$$

The reference strain $\varepsilon_{r e f}$ is composed of the elastic component $\varepsilon_{r e f}^{e}$ and plastic component $\varepsilon_{r e f}^{p}$, i.e. $\varepsilon_{r e f}=\varepsilon_{r e f}^{e}+\varepsilon_{r e f}^{p}$. By applying this equation to Eq. (15) yields

$$
\frac{J_{p}}{J_{e}} \approx \frac{E \varepsilon_{r e f}}{\sigma_{r e f}}-\frac{E \varepsilon_{r e f}^{e}}{\sigma_{r e f}} .
$$

Since $\varepsilon_{r e f}^{e} / \sigma_{r e f}=1 / E$ and the $J$ solution from Eq. (2), Eq. (16) can be written as

$$
\frac{J}{J_{e}} \approx \frac{E \varepsilon_{r e f}}{\sigma_{r e f}} .
$$

Reference [21] suggested that $J$ estimation in the small-scale yielding range can be improved by adding of the plasticity correction term $L_{r}^{2} \sigma_{r e f} / 2 E \varepsilon_{r e f}$. The RS-based $J$ estimation equation is finally written as

$$
\frac{J}{J_{e}}=\frac{E \varepsilon_{r e f}}{\sigma_{r e f}}+\frac{1}{2} \frac{L_{r}^{2} \sigma_{r e f}}{E \varepsilon_{r e f}} .
$$

The FAC is constructed by plotting the stress intensity factor ratio $K_{r}$ versus the load ratio $L_{r}$, where $K_{r}$ is defined as [21] 


$$
K_{r}=\sqrt{\frac{J_{e}}{J}}
$$

If the $J$ solution from finite element method (i.e. Eqs. (3) and (5)) is substituted into Eq. (19), the FEbased FAC is obtained. If the $J$ estimation equation by reference stress method (i.e. Eq. (18)) is used instead, the following RS-based FAC is obtained as

$$
K_{r}=\left[\frac{E \varepsilon_{r e f}}{\sigma_{r e f}}+\frac{1}{2} \frac{L_{r}^{2} \sigma_{r e f}}{E \varepsilon_{r e f}}\right]^{-\frac{1}{2}} .
$$
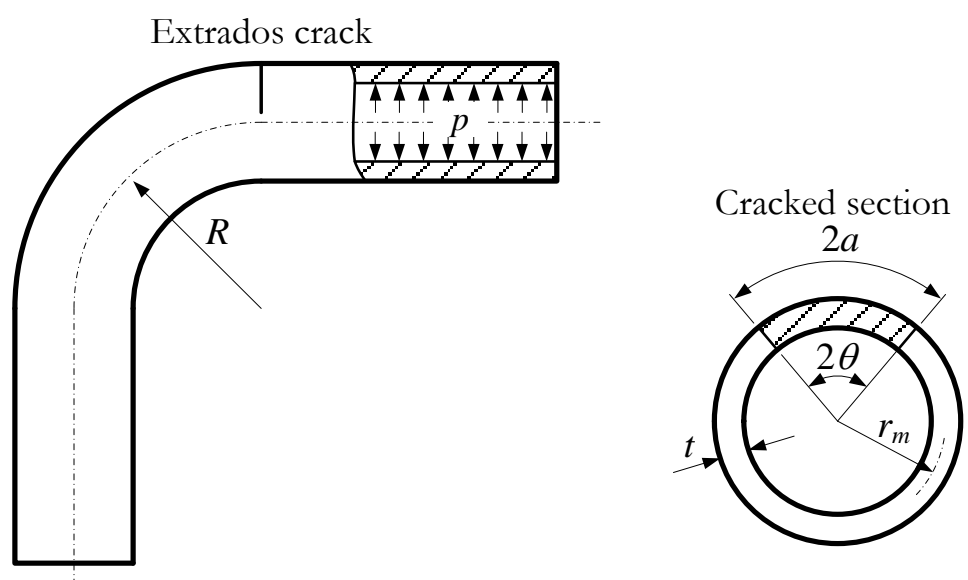

Fig. 1. Extrados through-wall crack at an interface between elbow and pipe under internal pressure.

\section{Reference Pressure}

This section summarizes the underlying data used in the determination of the reference pressure. After that, a procedure and criteria for determining the appropriate reference pressure are described. Lastly, the result is reported.

\subsection{Summary of the Data from the Literature}

Jang et al. [20] adopted the ABAQUS software in the FE analysis of the present problem and varied the ratio of pipe mean radius to wall thickness, $r_{m} / t$; the ratio of elbow bend radius to pipe mean radius, $R / r_{m}$; the normalized half crack angle, $\theta / \pi$, and the strain hardening exponent, $n$. The values of these parameters are $r_{m} / t=5,10,20$ and $30 ; R / r_{m}=2,3,4,5$ and $6 ; \theta / \pi=0.125,0.25,0.3,0.4$ and 0.5 ; and $n=1,3,5,7$ and 10 . Therefore, their analyses covered a total of 500 cases (or 100 geometries).

Due to the symmetry of component's geometries, the constructed FE model was only a half of an elbow with an attached straight pipe. The FE model used a 20-node isoparametric quadratic brick element with reduced integration. For all cases, five elements were used in the thickness direction and the number of elements and nodes of the models are 10,500 and 50,521, respectively. The internal pressure was applied as distributed load acting on the inner surface of the model. Effect of the end cap at the pipe's ends was replaced by an equivalent tensile force. The effect of crack face pressure on the fracture parameters was included by applying $50 \%$ of the internal pressure to the crack face of a through-wall crack.

The value of $J$ was determined by the domain integral method. The representative value of $J$ for each case was an average of $J$ from several paths along the thickness direction excluding the values from the path at innermost and outermost surfaces.

\subsection{Determination of the Reference Pressure}

Assume the reference pressure is related to the limit pressure by 


$$
p_{\text {ref }}=k p_{L},
$$

where $k$ is an undetermined function of component's geometrical variables and crack angle.

By substituting Eq. (21) into Eq. (8) yields

$$
h_{1}^{*}=h_{1}\left(\frac{r_{m}}{t}, \frac{R}{r_{m}}, \frac{\theta}{\pi}, n\right) \cdot k^{n+1} .
$$

To find the reference pressure for each set of $r_{m} / t, R / r_{m}$ and $\theta / \pi$, firstly, assume a specific value of $k$ and calculated the parameter $\Delta$ defined as

$$
\Delta=\sum_{s=1,3,5,7,10}\left[h_{1}(n=s) \cdot k^{n+1}-h_{1}(n=1) \cdot k^{2}\right]^{2},
$$

which represents the sum square of the deviation. Next, repeat the calculation until the value of $k$ that minimizes the parameter $\Delta$ is found. The values of $k$ obtained from this process are listed in Table 1 . It can be observed that the values of $k$ are depended on the normalized geometrical parameters, i.e. $r_{m} / t, R / r_{m}$ and $\theta / \pi$. Therefore, to facilitate an application of these results in the calculation of $J$ or construction of FAC, the following equation is proposed to fit the tabulated results.

$$
k=c_{1}(\lambda)\left(\frac{\theta}{\pi}\right)^{3}+c_{2}(\lambda)\left(\frac{\theta}{\pi}\right)^{2}+c_{3}(\lambda)\left(\frac{\theta}{\pi}\right)+c_{4}(\lambda),
$$

where $\lambda$ is a bending characteristic and is defined as

$$
\lambda \equiv \frac{R / r_{m}}{r_{m} / t}=\frac{R t}{r_{m}^{2}},
$$

and the functions $c_{1}(\lambda), c_{2}(\lambda), c_{3}(\lambda)$ and $c_{4}(\lambda)$ are given by:

$$
\begin{gathered}
c_{1}(\lambda)=24.928 \lambda^{2}-31.940 \lambda-10.139, \\
c_{2}(\lambda)=-19.962 \lambda^{2}+24.097 \lambda+10.700, \\
c_{3}(\lambda)=4.170 \lambda^{2}-4.537 \lambda-1.641, \\
c_{4}(\lambda)=-0.412 \lambda^{2}+0.524 \lambda+0.652 .
\end{gathered}
$$

Equation (24) can be used to estimate the tabulated values of $k$ in Table 1 with an accuracy within the range of -7.6 to $11.4 \%$.

\section{Validation and Discussion}

This section investigates the accuracy of the obtained reference pressure by comparing the RS-based FAC with the FE-based FAC. The accuracy of the RS-based FAC is quantitatively expressed by the parameter [18]

$$
Q=\frac{K_{r(r e f)}}{K_{r(F E M)}},
$$

where $K_{r(r e f)}$ and $K_{r(F E M)}$ as illustrated in Fig. 2 are the ordinates of the failure points on the FACs obtained by RS method and by FE method, respectively. The failure point is the intersection between a loading path and FAC. Note that the parameter $Q$ can be interpreted as the ratio of failure pressure obtained from the RSbased FAC to that obtained from the FE-based FAC. Thus, the value of $Q$ less than unity implies that the RS-based FAC predicts a more conservative failure pressure than the FE-based FAC. The value of $Q$ equal to unity represents the most accurate estimation of the FAC by the reference stress method. 
Table 1. Optimized values of $k$ for each elbow geometries and crack angles.

\begin{tabular}{|c|c|c|c|c|c|c|c|c|c|}
\hline \multirow[t]{2}{*}{ Case } & \multicolumn{3}{|c|}{ Geometrical variables } & \multirow[t]{2}{*}{$k$} & \multirow[t]{2}{*}{ Case } & \multicolumn{3}{|c|}{ Geometrical variables } & \multirow[t]{2}{*}{$\boldsymbol{k}$} \\
\hline & $r_{m} / t$ & $R / r_{m}$ & $\theta / \pi$ & & & $r_{m} / t$ & $R / r_{m}$ & $\theta / \pi$ & \\
\hline 1 & \multirow{25}{*}{5} & \multirow[t]{5}{*}{2} & 0.125 & 0.733 & 51 & \multirow{25}{*}{20} & \multirow{5}{*}{2} & 0.125 & 0.636 \\
\hline 2 & & & 0.25 & 0.901 & 52 & & & 0.25 & 0.788 \\
\hline 3 & & & 0.3 & 0.999 & 53 & & & 0.3 & 0.889 \\
\hline 4 & & & 0.4 & 1.212 & 54 & & & 0.4 & 1.087 \\
\hline 5 & & & 0.5 & 1.334 & 55 & & & 0.5 & 1.261 \\
\hline 6 & & \multirow[t]{5}{*}{3} & 0.125 & 0.714 & 56 & & \multirow[t]{5}{*}{3} & 0.125 & 0.635 \\
\hline 7 & & & 0.25 & 0.905 & 57 & & & 0.25 & 0.814 \\
\hline 8 & & & 0.3 & 1.012 & 58 & & & 0.3 & 0.931 \\
\hline 9 & & & 0.4 & 1.222 & 59 & & & 0.4 & 1.157 \\
\hline 10 & & & 0.5 & 1.327 & 60 & & & 0.5 & 1.309 \\
\hline 11 & & \multirow[t]{5}{*}{4} & 0.125 & 0.708 & 61 & & \multirow[t]{5}{*}{4} & 0.125 & 0.637 \\
\hline 12 & & & 0.25 & 0.909 & 62 & & & 0.25 & 0.831 \\
\hline 13 & & & 0.3 & 1.019 & 63 & & & 0.3 & 0.954 \\
\hline 14 & & & 0.4 & 1.222 & 64 & & & 0.4 & 1.191 \\
\hline 15 & & & 0.5 & 1.321 & 65 & & & 0.5 & 1.319 \\
\hline 16 & & \multirow[t]{5}{*}{5} & 0.125 & 0.705 & 66 & & \multirow[t]{5}{*}{5} & 0.125 & 0.640 \\
\hline 17 & & & 0.25 & 0.912 & 67 & & & 0.25 & 0.843 \\
\hline 18 & & & 0.3 & 1.022 & 68 & & & 0.3 & 0.968 \\
\hline 19 & & & 0.4 & 1.222 & 69 & & & 0.4 & 1.208 \\
\hline 20 & & & 0.5 & 1.316 & 70 & & & 0.5 & 1.319 \\
\hline 21 & & \multirow[t]{5}{*}{6} & 0.125 & 0.703 & 71 & & \multirow[t]{5}{*}{6} & 0.125 & 0.643 \\
\hline 22 & & & 0.25 & 0.913 & 72 & & & 0.25 & 0.851 \\
\hline 23 & & & 0.3 & 1.024 & 73 & & & 0.3 & 0.978 \\
\hline 24 & & & 0.4 & 1.221 & 74 & & & 0.4 & 1.216 \\
\hline 25 & & & 0.5 & 1.314 & 75 & & & 0.5 & 1.316 \\
\hline 26 & 10 & 2 & 0.125 & 0.683 & 76 & 30 & 2 & 0.125 & 0.608 \\
\hline 27 & & & 0.25 & 0.850 & 77 & & & 0.25 & 0.737 \\
\hline 28 & & & 0.3 & 0.954 & 78 & & & 0.3 & 0.822 \\
\hline 29 & & & 0.4 & 1.168 & 79 & & & 0.4 & 0.980 \\
\hline 30 & & & 0.5 & 1.305 & 80 & & & 0.5 & 1.142 \\
\hline 31 & & 3 & 0.125 & 0.675 & 81 & & 3 & 0.125 & 0.611 \\
\hline 32 & & & 0.25 & 0.866 & 82 & & & 0.25 & 0.772 \\
\hline 33 & & & 0.3 & 0.980 & 83 & & & 0.3 & 0.876 \\
\hline 34 & & & 0.4 & 1.203 & 84 & & & 0.4 & 1.069 \\
\hline 35 & & & 0.5 & 1.319 & 85 & & & 0.5 & 1.247 \\
\hline 36 & & 4 & 0.125 & 0.673 & 86 & & 4 & 0.125 & 0.615 \\
\hline 37 & & & 0.25 & 0.876 & 87 & & & 0.25 & 0.794 \\
\hline 38 & & & 0.3 & 0.994 & 88 & & & 0.3 & 0.908 \\
\hline 39 & & & 0.4 & 1.214 & 89 & & & 0.4 & 1.124 \\
\hline 40 & & & 0.5 & 1.315 & 90 & & & 0.5 & 1.296 \\
\hline 41 & & 5 & 0.125 & 0.674 & 91 & & 5 & 0.125 & 0.619 \\
\hline 42 & & & 0.25 & 0.883 & 92 & & & 0.25 & 0.809 \\
\hline 43 & & & 0.3 & 1.001 & 93 & & & 0.3 & 0.929 \\
\hline 44 & & & 0.4 & 1.217 & 94 & & & 0.4 & 1.160 \\
\hline 45 & & & 0.5 & 1.311 & 95 & & & 0.5 & 1.311 \\
\hline 46 & & 6 & 0.125 & 0.675 & 96 & & 6 & 0.125 & 0.623 \\
\hline 47 & & & 0.25 & 0.887 & 97 & & & 0.25 & 0.820 \\
\hline 48 & & & 0.3 & 1.006 & 98 & & & 0.3 & 0.944 \\
\hline 49 & & & 0.4 & 1.218 & 99 & & & 0.4 & 1.183 \\
\hline 50 & & & 0.5 & 1.308 & 100 & & & 0.5 & \\
\hline
\end{tabular}


The loading path for a component subjected to only a primary load (i.e. a pressure, herein) is a straight line passing through the origin of the FAD. Since the slope of this path depends on component geometrical variables and the crack length. Therefore, for each FAC, various loading paths were analyzed and the maximum deviations on the conservative side $(Q<1)$ and unconservative side $(Q>1)$ were determined.

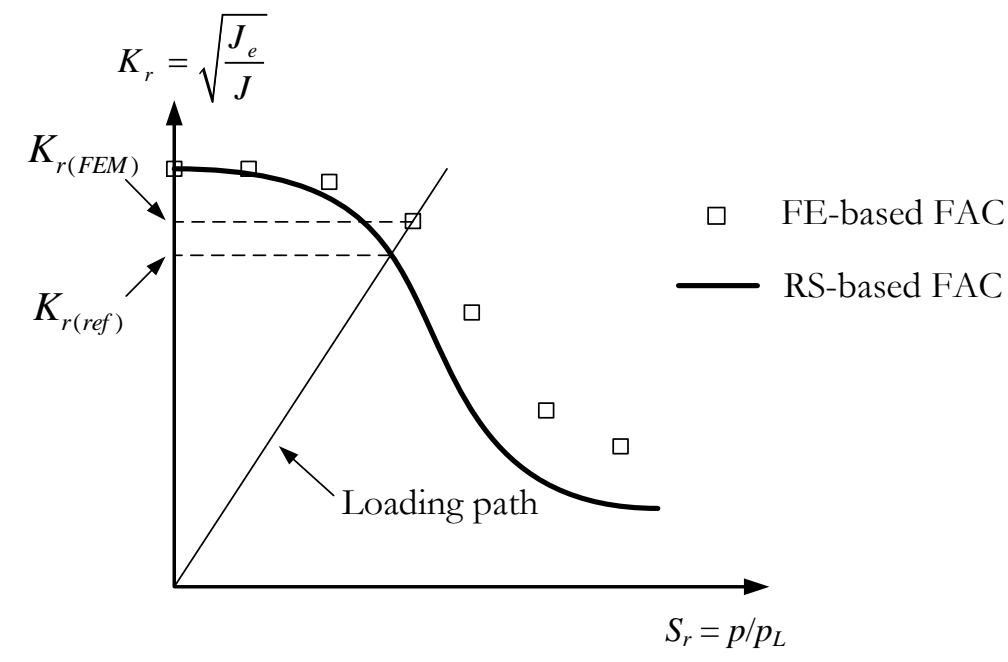

Fig. 2. Illustration of fracture assessment by FAD approach and definition of the parameter for indicating the accuracy of the RS-based FAC.

In practice, the FAC is a plot of $K_{r}$ versus $S_{r}$, where $S_{r}$ is also called the load ratio and it is defined as $S_{r}=p / p_{L}$. The relationship between both definitions of load ratio $\left(S_{r}\right.$ and $\left.L_{r}\right)$ can be derived by using Eq. (21) and it can be shown that $L_{r}=k S_{r}$. The RS-based FAC is now depended on the component's geometrical variables (i.e. $r_{m} / t, R / r_{m}$ ) and the normalized half crack angle (i.e. $\theta / \pi$ ) which is similar to the FE-based FAC. However, if the RS-based FAC is plotted against $L_{r}$, the curve will depend only on the material's stress-strain relation.

All verification cases adopted the RO stress-strain relation shown in Eq. (1). The chosen values of normalized geometrical parameters (i.e. $r_{m} / t, R / r_{m}$ and $\theta / \pi$ ) and the strain hardening exponent $n$ are summarized in Table 2. Group 1 investigates the effect of crack angle (or length) and strain hardening behavior (i.e. in terms of $n$ ). Group 2 investigates the effect of component geometry and strain hardening behavior.

Table 2. Verification cases.

\begin{tabular}{lllll}
\hline \multirow{2}{*}{ Group } & \multicolumn{3}{l}{ Geometrical variables } & \multirow{2}{*}{$\boldsymbol{n}$} \\
\cline { 2 - 5 } & $\boldsymbol{r}_{\boldsymbol{m}} / \boldsymbol{t}$ & $\boldsymbol{R} / \boldsymbol{r} \boldsymbol{\theta}$ & $\boldsymbol{\theta} \boldsymbol{\pi}$ & $3,5,7,10$ \\
\hline 1 & 5 & 3 & $0.125,0.25,0.5$ & 3,10 \\
\hline
\end{tabular}

The FACs from conditions in group 1 are shown in Fig. 3. The FACs from both approaches are comparable to each other. The condition $n=10$ and $\theta / \pi=0.125$ in Fig. 3(d) gives the highest deviation of the parameter $Q$ from unity (i.e. $Q=0.91$ ), which means that the RS-based FAC predicts a more conservative fracture load than that of the FE-based FAC by at most 9\%. The FACs from conditions in group 2 are shown in Figs. 4 and 5 for $n=3$ and 10, respectively. For all selected cases, the same level of agreement between the FACs by both approaches is obtained.

Analyses of all remaining cases found that the values of the parameter $Q$ were within the range of 0.89 to 1.07. This finding implies that the RS-based FAC predicts a failure load more conservative than the FEbased FAC by at most $11 \%$, and more unconservative than the FE-based FAC by at most $7 \%$. The average values of $Q$ are $0.97,0.95,0.93$ and 0.92 for $n=3,5,7$ and 10, respectively. This finding implies that the RSbased FAC tended to predict a conservative fracture load. Similar conclusions have been reported in Ref. [18] 
for the problem of pipe with a semi-elliptical circumferential crack subjected to a bending moment. Therefore, the obtained reference pressure and the estimated failure assessment curve by the reference stress method have a sufficient accuracy for fracture assessment of the present cracked component.

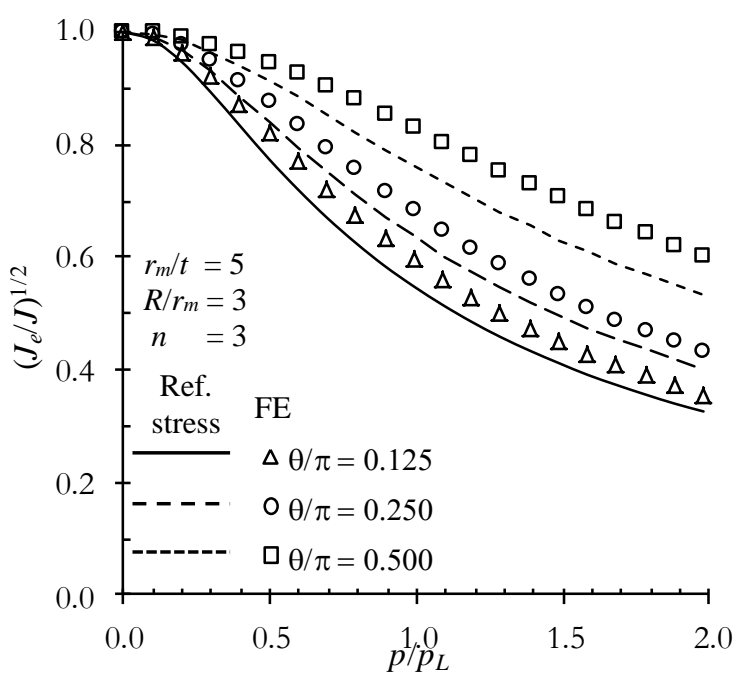

(a)

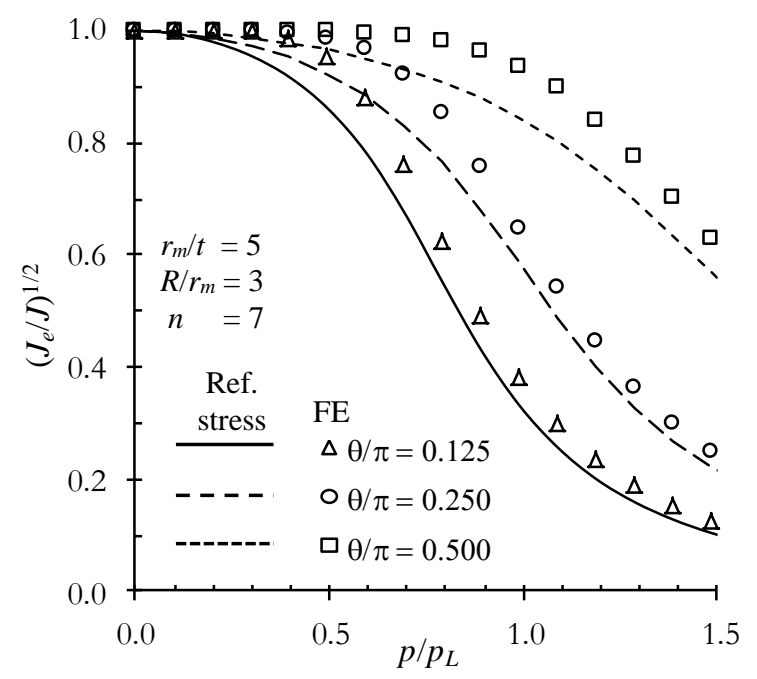

(c)

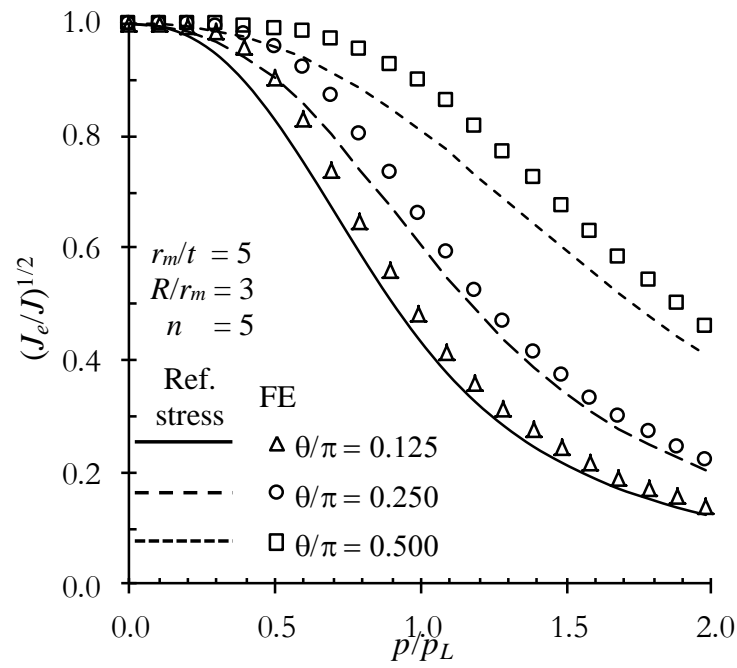

(b)

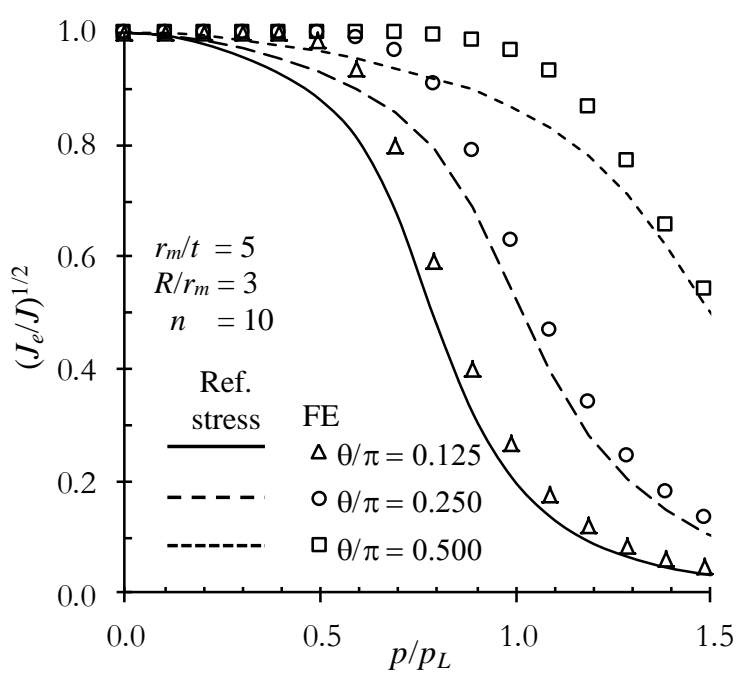

(d)

Fig. 3. Comparison of reference stress based FAC with finite element based FAC for various strain hardening behaviors and crack angles. 


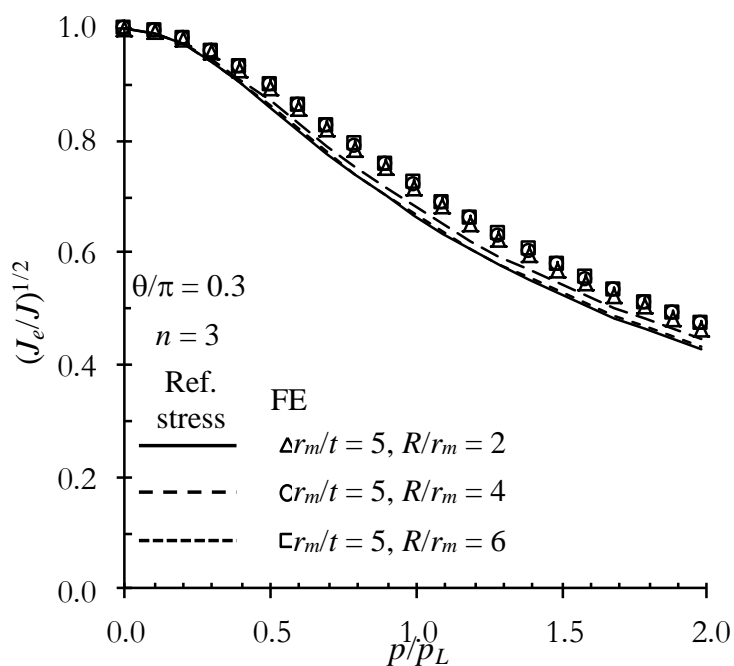

(a)

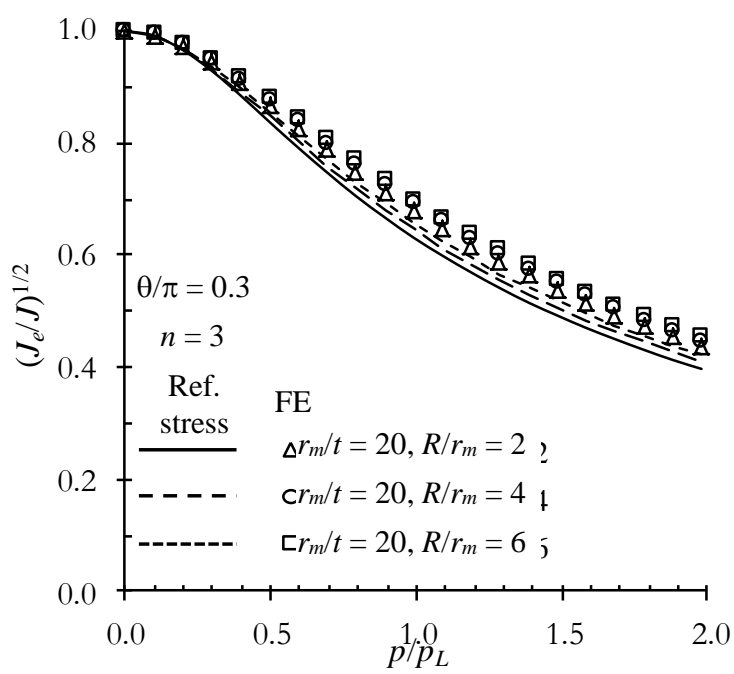

(c)

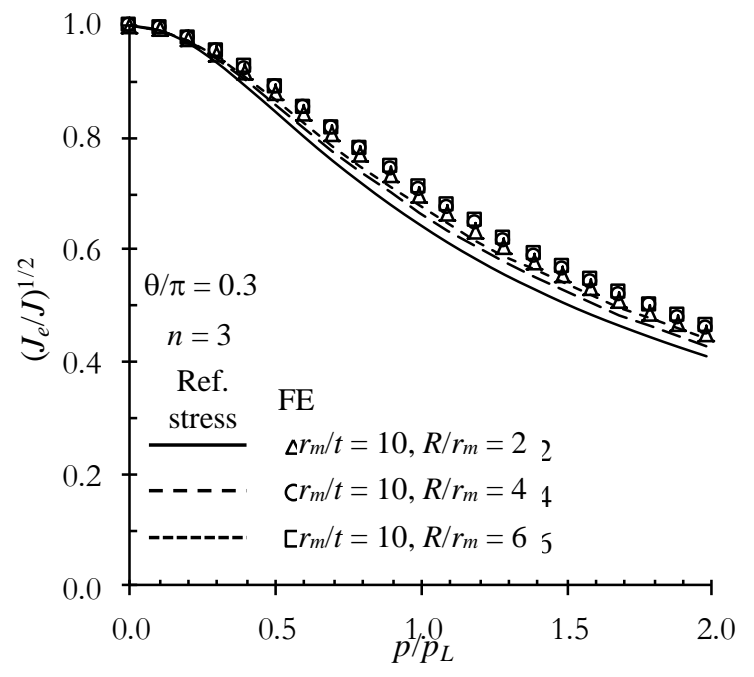

(b)

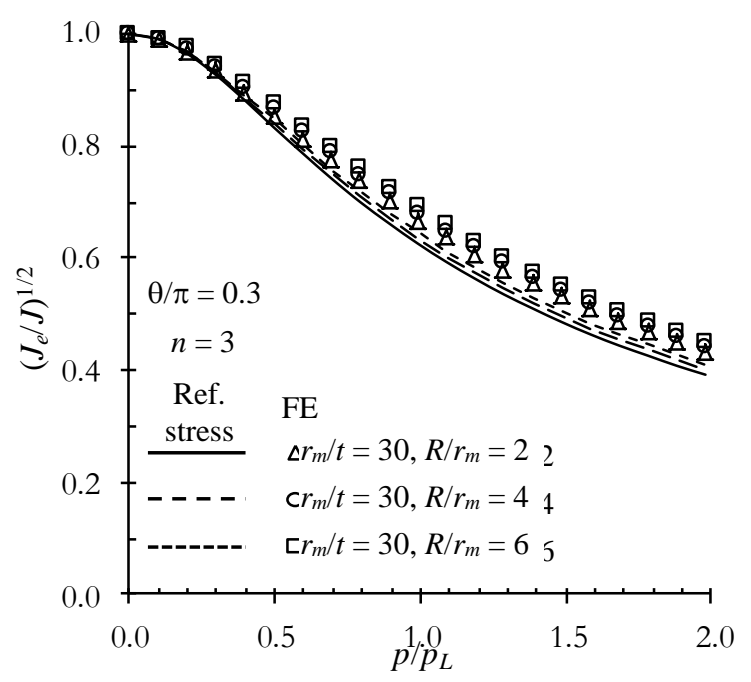

(d)

Fig. 4. Comparison of reference stress based FAC with finite element based FAC for various component's geometrical variables at a specific normalized half crack angle $\theta / \pi=0.3$ and $n=3$. 


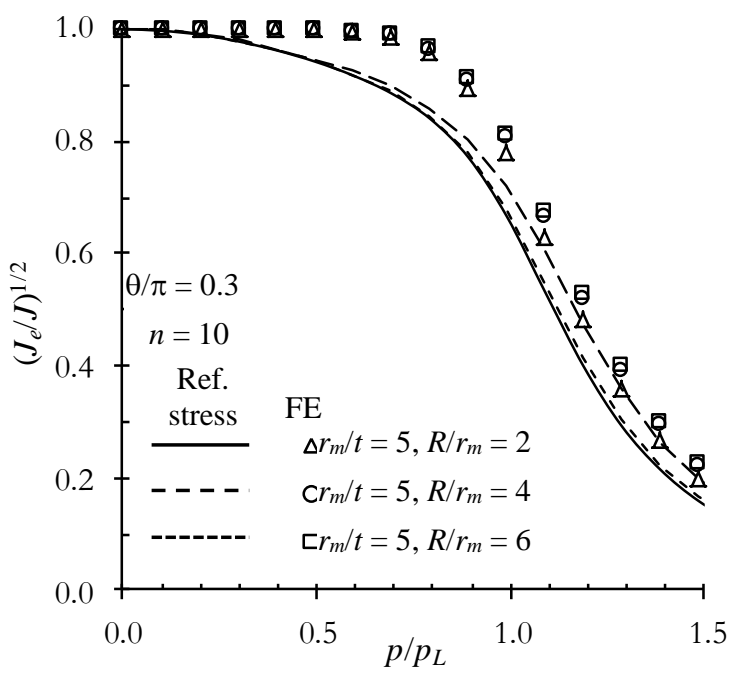

(a)

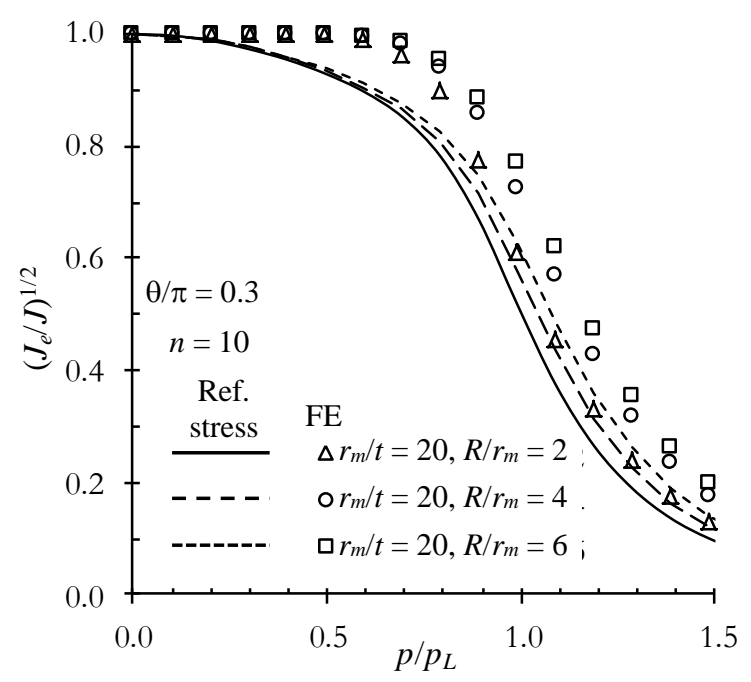

(c)



(b)

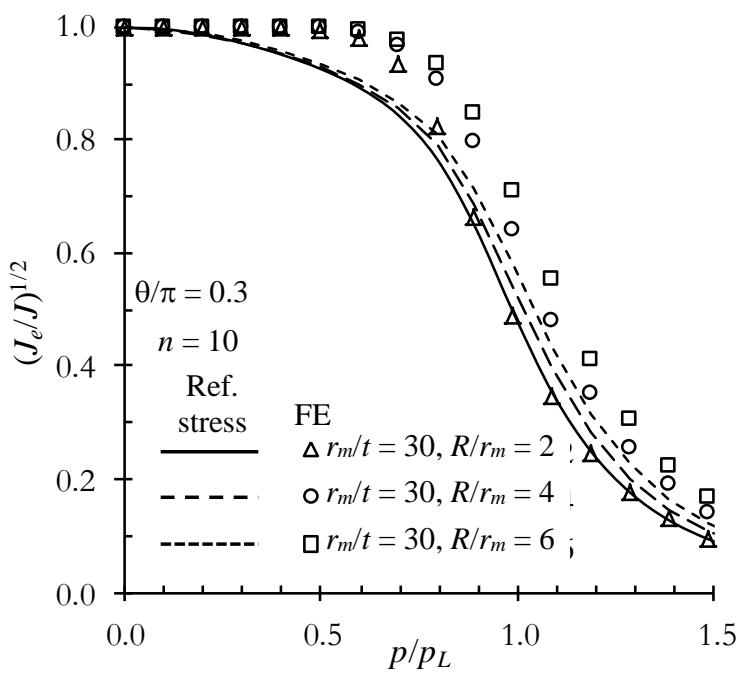

(d)

Fig. 5. Comparison of reference stress based FAC with finite element based FAC for various component's geometrical variables at a specific normalized half crack length $\theta / \pi=0.3$ and $n=10$.

\section{Conclusion}

The reference stress approach was applied to the problem of extrados through-wall crack at the interface between elbow and straight pipe under internal pressure. The finite element results from the literature were analyzed and the expression of optimized reference pressure for incorporating with the reference stress method was determined. This expression was evaluated by comparing the FACs obtained by the reference stress method with those obtained by the finite element method for the Ramberg-Osgood type material. The cases for comparisons covered the ratios of pipe mean radius to wall thickness, $r_{m} / t$, from 5 to 30 ; the ratios of elbow bend radius to pipe mean radius, $R / r_{m}$, from 2 to 6 ; the normalized half crack angles, $\theta / \pi$, from 0.125 to 0.5 ; and the strain hardening exponents $n$ from 1 to 10 . The RS-based FAC tended to predict a conservative fracture load as compared with those obtained from the FE-based FAC. Deviation of the RSbased FAC solutions from those of the FE-based FAC was within the range of -7\% to $11 \%$

\section{Acknowledgment}

The authors would like to acknowledge Prof. Nam-Su Huh and his research group for the contribution of their revised data in Ref. [20]. 


\section{References}

[1] ASME, "Part 9 Assessment of crack-like flaw," in API 579/ASME FFS-1 Recommended Practice for Fitnessfor-Service, 3rd ed. USA: API, 2016, pp. 9-1 - 9-65.

[2] V. Kumar, M. D. German, and C. F. Shih, "An engineering approach for elastic-plastic fracture analysis," EPRI Report, NP-1931, 1981.

[3] H. Xu, P. N. Li, Y. J. Xie, and Z. W. Wang, "J integral estimation fracture analysis for circumferentially cracked carbon steel piping," Nucl Eng Des, vol. 167, pp. 7-10, 1996.

[4] M. Kamaya, "Elastic-plastic failure assessment of cold worked stainless steel pipes," Int J Pres Ves Pip, vol. 131, pp. 45-51, 2015.

[5] M. Kamaya, "A J-integral estimation procedure for Swift-type stress-strain curves," Eng Fract Mech, vol. 127, pp. 31-45, 2014.

[6] R. A. Ainsworth, "The assessment of defects in structures of strain hardening material," Eng Fract Mech, vol. 19, no. 4, pp. 633-642, 1984.

[7] Y. J. Kim, N. S. Huh, Y. J. Park, and Y. J. Kim, "Elastic-plastic $J$ and COD estimates for axial throughwall cracked pipes," Int J Pres Ves Pip, vol. 79, pp. 451-464, 2002.

[8] Y. J. Kim, N. S. Huh, and Y. J. Kim, "Reference stress based elastic-plastic fracture analysis for circumferential through-wall cracked pipes under combined tension and bending," Eng Fract Mech, vol. 69, pp. 367-388, 2002.

[9] Y. J. Kim and P. J. Budden, "Reference stress approximations for $J$ and COD of circumferential through-wall cracked pipes," Int J Fracture, vol. 116, pp. 195-218, 2002.

[10] Y. J. Kim, J. S. Kim, Y. Z. Lee, and Y. J. Kim, "Non-linear fracture mechanics analyses of part circumferential surface cracked pipe," Int J Fracture, vol. 116, pp. 347-375, 2002.

[11] C. S. Oh, T. K. Song, Y. J. Kim, J. S. Kim, and T. E. Jin, "Approximate J estimates for axial part-through surface-cracked pipe," Fract Engng Mater Struct, vol. 30, pp. 1127-1139, 2007.

[12] D. H. Cho, H. B. Seo, Y. J. Kim, Y. S. Chang, M. J. Jhung, and Y. H. Choi, "Advances in J-integral estimation of circumferentially surface cracked pipes," Fract Engng Mater Struct, vol. 34, pp. 667-681, 2011.

[13] N. H. Kim, C. S. Oh, Y. J. Kim, J. S. Kim, D. W. Jerng, and P. J. Budden, "Limit loads and fracture mechanics parameters for thick-walled pipes," Int J Pres Ves Pip, vol. 88, pp. 403-414, 2011.

[14] Y. J. Kim, T. K. Song, J. S. Kim, and T. E. Jin, "Limit loads and approximate $J$ estimates for axial through-wall cracked pipe bends," Int J Fract, vol. 146, pp. 249-264, 2007.

[15] C. G. Kim, K. D. Bae, Y. J. Kim, Y. J. Oh, and P. J. Budden, "Reference stress based J and COD estimation of circumferential through-wall cracked elbows under in-plane bending," Eng Fract Mech, vol. 142, pp. 303-317, 2015.

[16] C. K. Oh, T. K. Song, Y. J. Kim, J. S. Kim, and T. E. Jin, "Elastic-plastic fracture mechanics analyses of circumferential through-wall cracks between elbows and pipes," Eng Fract Mech, vol. 75, pp. 12311250. 2008.

[17] T. K. Song, Y. J. Kim, C. K. Oh, T. E. Jin, and J. S. Kim, "Net-section limit moments and approximate $J$-estimates for circumferential cracks at the interface between elbows and pipes," Int J Pres Ves Pip, vol. 86, pp. $495-507,2009$.

[18] M. Kamaya and H. Machida, "Reference stress method for evaluation of failure assessment curve of cracked pipes in nuclear power plants," Int J Pres Ves Pip, vol. 87, pp. 66-73, 2010.

[19] Y. Y. Jang, J. U. Jeong, N. S. Huh, K. S. Kim, and W. Y. Cho, "Closed-form solutions for stress intensity factor and elastic crack opening displacement for circumferential through-wall cracks in the interface between an elbow and a straight pipe under internal pressure," Journal of the Korean Society of Manufacturing Technology Engineers, vol. 24, no. 5, pp. 553-560, 2015.

[20] Y. Y. Jang, J. U. Jeong, and N. S. Huh, "Prediction of fracture parameters of circumferential throughwall cracks in the interface between an elbow and a pipe under internal pressure," J of Mech Sci Technol, vol. 30, no. 9, pp. 4217-4226, 2016.

[21] I. Milne, R. A. Ainsworth, A. R. Dowling, and A. T. Stewart, "Assessment of the integrity of structures containing defects," Int J Pres Ves Pip, vol. 32, pp. 3-104, 1988. 


\section{Appendix A: Stress intensity factor $(K)$ solution}

The following $K$ solution is taken from Ref. [19].

$$
\begin{gathered}
K=\frac{p}{2}\left(\frac{r_{m}}{t}-\frac{1}{2}\right) \sqrt{\pi a} \cdot F \\
F=1+a_{1}\left(\frac{\theta}{\pi}\right)+a_{2}\left(\frac{\theta}{\pi}\right)^{2}+a_{3}\left(\frac{\theta}{\pi}\right)^{3}+a_{4}\left(\frac{\theta}{\pi}\right)^{4} \\
a_{1}=2.299-0.070\left(\frac{r_{m}}{t}\right)+0.002\left(\frac{r_{m}}{t}\right)^{2}-1.215\left(\frac{r_{m}}{R}\right)-0.133\left(\frac{r_{m}}{t}\right)\left(\frac{r_{m}}{R}\right)-0.003\left(\frac{r_{m}}{t}\right)^{2}\left(\frac{r_{m}}{R}\right) \\
a_{2}=-0.072+1.293\left(\frac{r_{m}}{t}\right)-0.004\left(\frac{r_{m}}{t}\right)^{2}-5.450\left(\frac{r_{m}}{R}\right)+5.943\left(\frac{r_{m}}{t}\right)\left(\frac{r_{m}}{R}\right)-0.010\left(\frac{r_{m}}{t}\right)^{2}\left(\frac{r_{m}}{R}\right) \\
a_{3}=2.414-3.060\left(\frac{r_{m}}{t}\right)-0.027\left(\frac{r_{m}}{t}\right)^{2}+30.200\left(\frac{r_{m}}{R}\right)-21.900\left(\frac{r_{m}}{t}\right)\left(\frac{r_{m}}{R}\right)+0.120\left(\frac{r_{m}}{t}\right)^{2}\left(\frac{r_{m}}{R}\right) \\
a_{4}=24.500+2.180\left(\frac{r_{m}}{t}\right)+0.050\left(\frac{r_{m}}{t}\right)^{2}-35.600\left(\frac{r_{m}}{R}\right)+22.300\left(\frac{r_{m}}{t}\right)\left(\frac{r_{m}}{R}\right)-0.180\left(\frac{r_{m}}{t}\right)^{2}\left(\frac{r_{m}}{R}\right)
\end{gathered}
$$

